\title{
Geometric analysis of soft thresholds in action potential initiation and the consequences for understanding phase response curves and model tuning
}

\author{
Robert Clewley ${ }^{1,2^{*}}$, Bryce Chung ${ }^{1}$ \\ From Twenty First Annual Computational Neuroscience Meeting: CNS*2012 \\ Decatur, GA, USA. 21-26 July 2012
}

Recent mathematical and computational work on the space-clamped Hodgkin-Huxley $(\mathrm{H}-\mathrm{H})$ model of neural excitability identifies major dynamic features of the changing nullclines in 2D phase plane projections during action potential (AP) initiation [1,2]. Such analysis provides novel mechanistic and geometric understanding (in terms of interplay between variables and currents) of the "soft threshold" dynamics. We perform visualization of the nullcline dynamics around threshold, and characterize important geometric properties via "dominant scale analysis" [3], which avoids the need to make asymptotic approximations. In particular, we analyze the transient dynamics during the passage through the ghost of a saddle-node bifurcation in the $(V, m)$ phase-plane projection of a local 3D approximation to the $4 \mathrm{D} \mathrm{H}-\mathrm{H}$ equations (where sodium inactivation $h$ is held constant). Linear analysis of the moving $V$-nullcline in these projections indicates that a necessary condition for AP initiation is the eventual holding of the following inequalities in the neighborhood of the ghost of the saddle node:

$$
\dot{V}_{\infty}-\dot{V}=\frac{\partial V_{\infty}}{\partial m} \dot{m}+\frac{\partial V_{\infty}}{\partial n} \dot{n}-\dot{V}>0 \text { and } \dot{n}>0,
$$

where the asymptotic steady state voltage $V_{\infty}(m, n)$ is for constant $h$. Given that $\frac{\partial V_{\infty}}{\partial m}>0$ and $\frac{\partial V_{\infty}}{\partial n}<0$ in this neighborhood, the first inequality can be interpreted as saying that the fast sodium current must dominate the

* Correspondence: rclewley@gsu.edu

${ }^{1}$ Neuroscience Institute, Georgia State University, Atlanta, GA 30303, USA

Full list of author information is available at the end of the article effect of the growing delayed rectifier potassium current, but not in such a way that $\dot{V}$ becomes large too rapidly. We find that the curvature of the nullclines in this region is responsible for the truth of this condition (for standard parameter values used for Type I and II modes of $\mathrm{H}-\mathrm{H}$ excitability).

We compare different parameter regimes for periodic and transient trajectories using our analysis. Under mild variation of parameters and initial conditions, and except in pathological circumstances that are related to the generation of sub-threshold oscillations and canards (e.g., see ref. [2]), we can predict the onset of AP initiation and its timing as the result of parameter changes or small voltage perturbations. This leads to insight about the origin of phase response curve shape in Type I vs. Type II neural excitability. Geometric features of the nullclines are measured during this analysis using PyDSTool [4], and the curvature conditions can be used to guide objective function choice for parameter tuning tasks where AP generation is found to be incomplete or imperfect (e.g., compare refs. [5,6]). This has applications in situations where APs are pathologically changed due to genetic channel defects (especially in potassium channels), or where unwanted depolarization block occurs.

\section{Acknowledgement}

This research is supported in part by NSF EMT/BSSE award \#0829742.

\section{Author details}

'Neuroscience Institute, Georgia State University, Atlanta, GA 30303, USA.

2Department of Mathematics and Statistics, Georgia State University, Atlanta, GA 30303, USA. 


\section{References}

1. Clewley R: Encoding the Fine-Structured Mechanism of Action Potential Dynamics with Qualitative Motifs. J Comput Neurosci 2011, 30(2):391-408.

2. Rubin J, Wechselberger M: Giant squid-hidden canard: the 3D geometry of the Hodgkin-Huxley model. Biol Cybern 2007, 97:5-32.

3. Clewley R, Soto-Trevino C, Nadim F: Dominant ionic mechanisms explored in the transition between spiking and bursting using local lowdimensional reductions of a biophysically realistic model neuron. $J$ Comput Neurosci 2009, 26(1):75-90.

4. Clewley RH, Sherwood WE, LaMar MD, Guckenheimer JM: PyDSTool, a software environment for dynamical systems modeling. 2007 [http:// pydstool.sf.net].

5. Druckmann S, Banitt Y, Gidon A, Schurmann F, Markram H, Segev I: A Novel Multiple Objective Optimization Framework for Constraining

Conductance-Based Neuron Models by Experimental Data. Frontiers in Neuroscience 2007, 1(1):7-18.

6. Clewley R, Dobric M: A qualitative optimization technique for biophysical neuron models with many parameters. BMC Neuroscience 2010, 11(Suppl 1):P39, doi:10.1186/1471-2202-11-S1-P39.

doi:10.1186/1471-2202-13-S1-P165

Cite this article as: Clewley and Chung: Geometric analysis of soft thresholds in action potential initiation and the consequences for understanding phase response curves and model tuning. BMC Neuroscience 2012 13(Suppl 1):P165.

\section{Submit your next manuscript to BioMed Central} and take full advantage of:

- Convenient online submission

- Thorough peer review

- No space constraints or color figure charges

- Immediate publication on acceptance

- Inclusion in PubMed, CAS, Scopus and Google Scholar

- Research which is freely available for redistribution

Submit your manuscript at www.biomedcentral.com/submit
C Biomed Central 